Review

\title{
Review of the Thermo-Physical Properties and Performance Characteristics of a Refrigeration System Using Refrigerant-Based Nanofluids
}

\author{
Mahesh Suresh Patil ${ }^{1}$, Sung Chul Kim ${ }^{2}$, Jae-Hyeong Seo ${ }^{3}$ and Moo-Yeon Lee ${ }^{1, *}$ \\ Received: 5 October 2015; Accepted: 21 December 2015; Published: 31 December 2015 \\ Academic Editor: Chi-Ming Lai \\ 1 Department of Mechanical Engineering, Dong-A University, Hadan 840, Saha-gu, Busan 604-714, Korea; \\ msp692@gmail.com \\ 2 School of Mechanical Engineering, Yeungnam University, 280 Daehak-Ro, Gyeongsan, Gyeongbuk 712-749, \\ Korea; sungkim@ynu.ac.kr \\ 3 R \& D Division, NTF Tech Co., Hadan 840, Saha-gu, Busan 604-714, Korea; cheonchw@naver.com \\ * Correspondence: mylee@dau.ac.kr; Tel./Fax: +82-51-200-7642
}

\begin{abstract}
Nanofluids are considered a promising choice for several heat transfer applications. With the increasing awareness for energy saving and efficiency improvement in various thermal systems, including refrigeration systems, there is a growing interest in the refrigerant-based nanofluids owing to their superior thermo-physical properties. Nanorefrigerants are a class of nanofluid, which consist of suspended nanoparticles in a base refrigerant. In this paper, it is intended to include many articles on refrigeration systems that use nanorefrigerants, published in the period from 2005 to 2015. Although this is an extensive review, it could not include all the papers, and only some major research works were selected. It is believed that the dependency of thermal conductivity and other properties on temperature will make the thermal systems more efficient while operating at a high temperature. The literature reviews associated with the performance characteristics of nanorefrigerants in refrigeration systems for the last 10 years have been compiled and presented in this paper. Furthermore, recent studies related to thermo-physical properties of nanorefrigerants and nanolubricants have also been summarized and reviewed in this paper.
\end{abstract}

Keywords: nanorefrigerants; nanolubricants; nanofluid; refrigeration systems; performance

\section{Introduction}

Nanofluids are a newly developed class of fluid in which nano-size particles are suspended in the base fluid. Various researchers have investigated the heat transfer characteristics and potential usage of nanofluids in several applications. Wen et al. [1] presented a critical review of the research on heat transfer applications of nanofluids, and discussed the inconsistency and controversy in various results associated with nanofluids. For example, some investigations [2,3] reported an increase in boiling heat transfer of nanofluids, and Bang et al. [4] have reported the decrease in boiling heat transfer of nanofluids. The results seem conflicting with the same nanoparticles and similar test conditions. In addition, the critical heat flux enhancement reported to vary from $10 \%-40 \%$ [4] to $200 \%-400 \%$ [5], which indicates the lack of knowledge of mechanism and parametric effect on heat transfer properties of nanofluids. Some reasons for these contradictions may be the failure of surfactant at high temperature. Torii [6] investigated the possibility of using nanofluids as the working fluid in heat exchangers. Sözen et al. [7] assessed the impact of a mixture of cooling/absorption fluid with $\mathrm{Al}_{2} \mathrm{O}_{3}$ nanoparticles. Saidur et al. [8] presented a review on the application of nanofluids and the challenges involved in their usage. The fluids currently used in various heat transfer applications, 
such as refrigeration, air-conditioning, coolants, and lubricants, have good compatibility with those systems. However, the inherent low thermal conductivity of these fluids makes most of the operating thermal systems less efficient. Previously, attempts have been made to use micro-sized metal particles to enhance the thermal conductivity of the mixture. However, these attempts had failed because of the poor suspension of the particles and clogging of the mixture. Considering better suspension stability and advancement of production techniques, nanofluids are a promising option for use as a more efficient heat transfer fluid. For example, Yant et al. [9] found that $0.3 \mathrm{wt} \%$ MWCNT-R141b refrigerant-based nanofluid had the optimum heat transfer enhancement, with maximum Nusselt numbers higher by $40 \%$ as compared to the base refrigerant.

Energy scarcity and depletion of conventional energy resources are some of the most important problems faced by the world today [10]. Energy needs are increasing rapidly, and there is an urgent need to develop more efficient thermal systems and reduce the usage of ineffective methods of heat transfer. Refrigeration and air conditioning systems constitute a large part of energy consumption worldwide. The Montreal protocol (1987) and Kyoto protocol (1997) have prohibited the use of the factors responsible for ozone layer depletion and global warming, respectively. Although chlorofluorocarbons (CFCs) and hydrochlorofluorocarbons (HCFCs) are efficient refrigerants, they have been outlawed worldwide for having high ozone depletion potential (ODP). Moreover, there is a growing urgency to reduce the usage of hydrofluorocarbons (HFCs), which have high global warming potential (GWP). The coefficient of performance (COP) of a refrigeration system is defined as the ratio of heat removal rate on the evaporator side to the mechanical work input on the compressor side. The COP can be upgraded in two ways: firstly, by increasing the heat removal rate at the evaporator side, and secondly, by decreasing the compressor work. Many researchers have investigated the possibility of introducing nanoparticles in refrigerants to develop a new class of nanofluids called "nanorefrigerants", and investigated their performance and applications. Some researchers have studied the application of nanoparticles in the lubricating oil of a compressor to reduce the compressor work.

In the literature reviews related to nanorefrigerants, most reviewers have focused on thermo-physical properties, and preparation and applications of nanorefrigerants. Alawi et al. [11] reviewed the thermal-physical properties of nanoparticles suspended in the nanorefrigerant and nanolubricants of refrigeration systems. The authors also presented the nanorefrigerant studies related to the heat transfer, pressure drop flow and pool boiling. Cheng et al. [12] conducted a comprehensive review of the refrigerant-based nanofluids for boiling and two-phase phenomena, and concluded that there are many unresolved problems associated with these phenomena. The authors also reviewed the effects of nanolubrication on boiling and two-phase flow phenomena. Sidik et al. [13] presented a comprehensive review of nucleate pool boiling, flow boiling, condensation, and two-phase flow of refrigerant-based nanofluids. Celen et al. [14] presented a review on the nanofluid flow characteristics and tried to clarify the effect of nanorefrigerant properties on heat transfer and pressure drop as compared to a base refrigerant. Although comprehensive reviews of the performance of the nanorefrigerants have been carried out in the past, to the authors' best knowledge, an intensive review for the period from 2005 to 2015 has not been carried out [15]. Thus, the research trends on the performance characteristics of many refrigeration systems using nanorefrigerants are surveyed, and specifically, concise and precise reviews on related papers published in the period from 2005 to 2015 have been considered for providing the intensive data and core information for researchers and engineers working for development of highly efficient refrigeration systems as well as thermal systems. Therefore, the objective of this review summarizes the work carried out on the thermo-physical properties and performance characteristics of the nanorefrigerants used in the refrigeration systems.

\section{Thermo-Physical Properties}

All the heat transfer applications are bounded by the finite values of thermo-physical properties in any heat transfer media. These properties play a crucial role in deciding the magnitude of heat transfer. Philip et al. [16] reviewed the thermal properties of nanofluids. Active or passive techniques can be 
used to change the heat transfer performance. Active techniques include mechanical operations like vibrations and related operations. Passive techniques include customization of fluid properties and changing the surface area and shape. Passive techniques are cheaper, convenient, and more effective. Enhancing the heat transfer performance by suspending nanoparticles in a base fluid comes under the category of passive technique. Recently, there have been many investigations to increase the heat transfer performance in refrigeration systems using nanorefrigerants and nanolubricants. Therefore, the quantification of the effect of variations in volume concentration and geometric features, such as size and shape, on the thermo-physical properties of nanorefrigerants and nanolubricants, and performance of refrigeration systems was mainly considered in this part.

\subsection{Thermal Conductivity}

To assess the heat transfer potential of a nanorefrigerant, it is important to know its thermal conductivity. Quantitatively, the value of the thermal conductivity of a medium shows its ability to transfer heat. The need to develop more efficient systems with higher heat transfer and to understand the underlying mechanism of heat transfer were the main driving forces for the numerous investigations carried out on the thermal conductivity of nanofluids. A benchmark experimental study on thermal conductivity of nanofluids "International Nanofluid Property Benchmark Exercise (INPBE)" [17] was carried out by a group of more than 30 organizations using different experimental methods. The effects of the experimental approach on the thermal conductivity have been discussed in this report. This investigation shows that the different measurement techniques can affect the measured value of thermal conductivity. For example, in thermal hot wire (THW) apparatus with or without insulation can give different thermal conductivity value due to current leakage into the fluid. However, very little investigations have been carried out on the thermal conductivity of nanorefrigerants. Very few notable investigations have been conducted experimentally and numerically to determine the thermal conductivity of a nanorefrigerant in the last decade [18]. Peng et al. [19] have experimentally investigated the thermal conductivity of a nanorefrigerant, and proposed a model to predict the thermal conductivity. The authors used spherical nanoparticles of copper, aluminum, nickel, copper oxide, and aluminum oxide with mean diameters of 25, 18,20,40, and $20 \mathrm{~nm}$, respectively, in R-113 refrigerant. The authors concluded that with increase in nanoparticle concentration, the thermal conductivity increases sharply. Additionally, they reported that for the same volume concentration, the thermal conductivity values for different types of nanoparticles showed little variation. Alawi et al. [20] used the thermal conductivity model developed by Koo and Kleinstreuer [21] which takes the effects of particle size, particle volume fraction, Brownian motion and temperature dependence into consideration and found that the increase in thermal conductivity of a nanorefrigerant was $141 \%$ for $5 \mathrm{vol} \%$ concentration of spherical CuO/R134a. The authors found a $43 \%$ increase in thermal conductivity at a temperature of $325 \mathrm{~K}$ for $5 \mathrm{vol} \%$ nanoparticle concentration. They also deduced that the variation in thermal conductivity is proportional to temperature. Figure 1 shows the variation in thermal conductivity of $\mathrm{CuO} / \mathrm{R} 134 \mathrm{a}$ nanorefrigerant as a function of particle concentration. Mahbubul et al. [22] investigated the effect of volume concentration and temperature on $\mathrm{Al}_{2} \mathrm{O}_{3} / \mathrm{R} 141 \mathrm{~b}$ nanorefrigerant. In an experimental investigation on $\mathrm{Al}_{2} \mathrm{O}_{3}$ nanoparticle having a mean diameter of $13 \mathrm{~nm}$, the authors varied the volume concentration and temperature from $0.5 \%$ to $2 \%$ and 5 to $20{ }^{\circ} \mathrm{C}$, respectively, and found that for $2 \mathrm{vol} \%$ concentration, the thermal conductivity enhancement was $141 \%$ as compared to the base fluid. While investigating for effects of temperature on thermal conductivity, they reported that the thermal conductivity was 1.626 times more as compared to base fluid at $2 \mathrm{vol} \%$ concentration and at $20^{\circ} \mathrm{C}$. An increase in temperature causes an increase in the Brownian motion in nanorefrigerants, which enhances the contribution from micro-convention, thereby increasing the heat transfer. Mahbubul et al. [23] used the thermal conductivity model proposed by Sitprasert et al. [24], which considers the effects of a temperature-dependent interfacial layer along with particle size and concentration. The authors stressed that the results obtained are more accurate than those obtained using the Leong et al. model [25], which assumed $1 \mathrm{~nm}$ thickness for the interfacial 
layer. Further, the particle size was varied from 5 to $25 \mathrm{~nm}$ instead of having a fixed value of $30 \mathrm{~nm}$, and the effect of this variation was investigated.

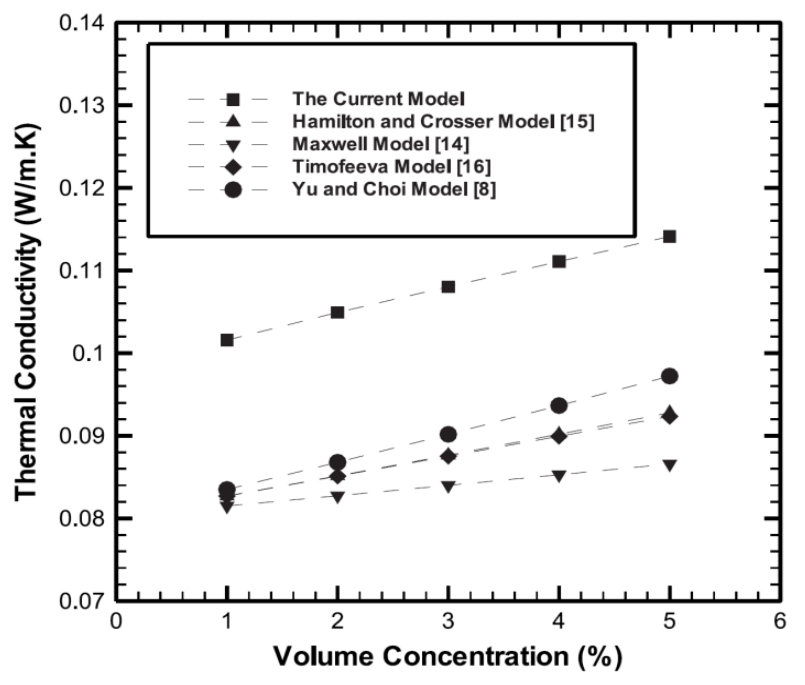

Figure 1. Variation in thermal conductivity of $\mathrm{CuO} / \mathrm{R} 134 \mathrm{a}$ as a function of particle volume fraction (at $300 \mathrm{~K})$ [20].

Figure 2 shows that the ratio of effective thermal conductivity of the nanofluid to the thermal conductivity of the base fluid of $\mathrm{Al}_{2} \mathrm{O}_{3} / \mathrm{R}-134$ a nanorefrigerant reduces with an increase in the particle size of $\mathrm{Al}_{2} \mathrm{O}_{3}$. This is due to the influence of the nanolayer or the interfacial layer. Because of the increase in surface area, the effect of interfacial layer increases, resulting in the increase in thermal conductivity. To investigate the effect of temperature on thermal conductivity, the temperature was varied from 300 to $325 \mathrm{~K}$. Figure 3 shows that a maximum increase of $43 \%$ in thermal conductivity was found at $325 \mathrm{~K}$ with $5 \mathrm{vol} \%$ concentration of nanoparticles. At a temperature of $300 \mathrm{~K}$ with $1 \mathrm{vol} \%$ nanoparticle concentration, the thermal conductivity was found to be minimal with only $4 \%$ increase. Figure 3 shows that the thermal conductivity is proportional to temperature, and that the variation is less for lower temperatures and with low volume concentration of nanoparticles. These findings will be useful in various applications. Figure 4 shows a comparison of the results of the study of thermal conductivity on $\mathrm{Al}_{2} \mathrm{O}_{3} / \mathrm{R} 134$ a nanorefrigerant with those of previously carried out work with different nanorefrigerants. The CNT based refrigerant is found to have higher thermal conductivity owing to the superior thermal conductivity of CNT particles.

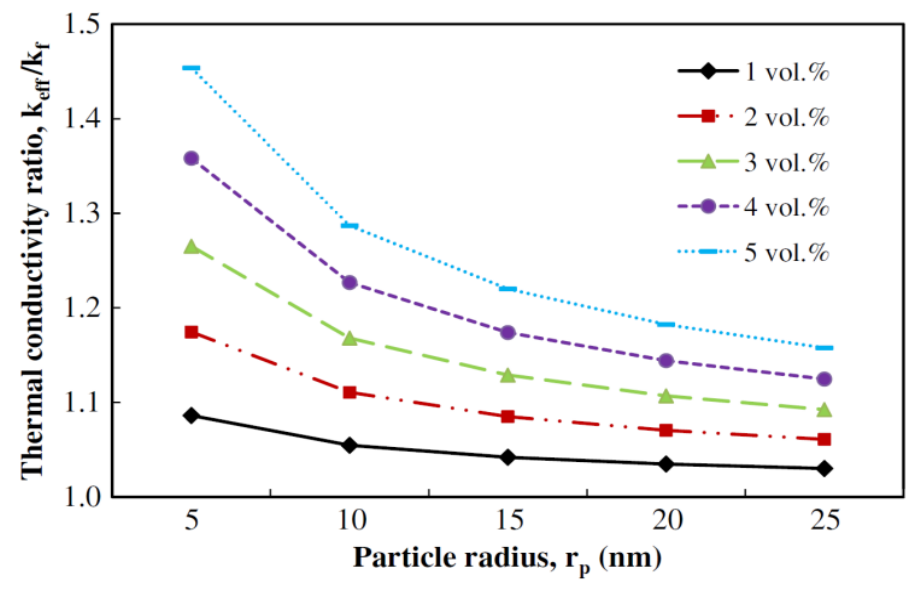

Figure 2. Thermal conductivity ratio as a function of particle size [23]. 


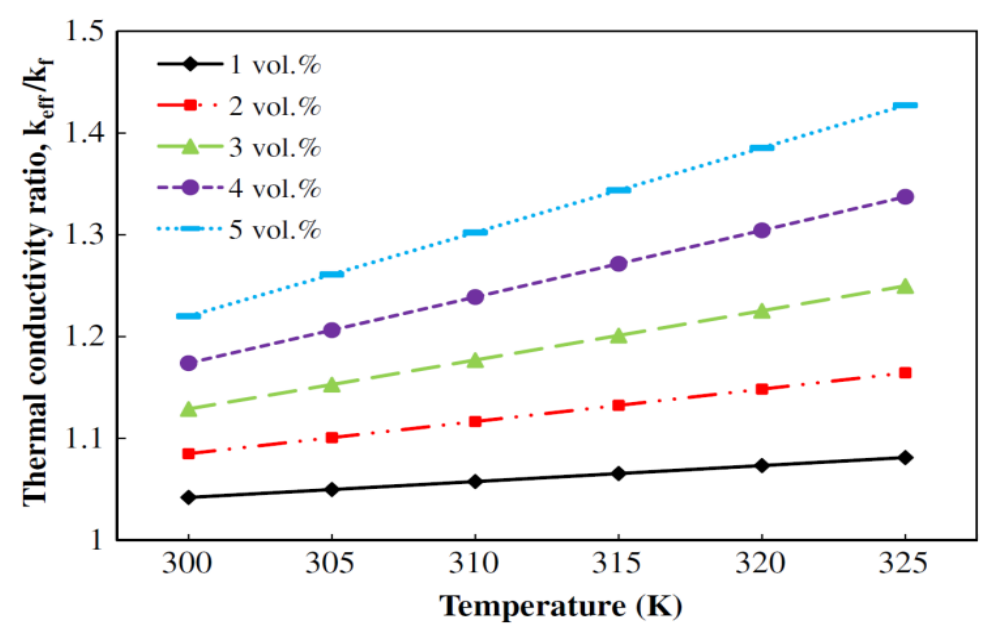

Figure 3. Thermal conductivity ratio as a function of temperature [23].

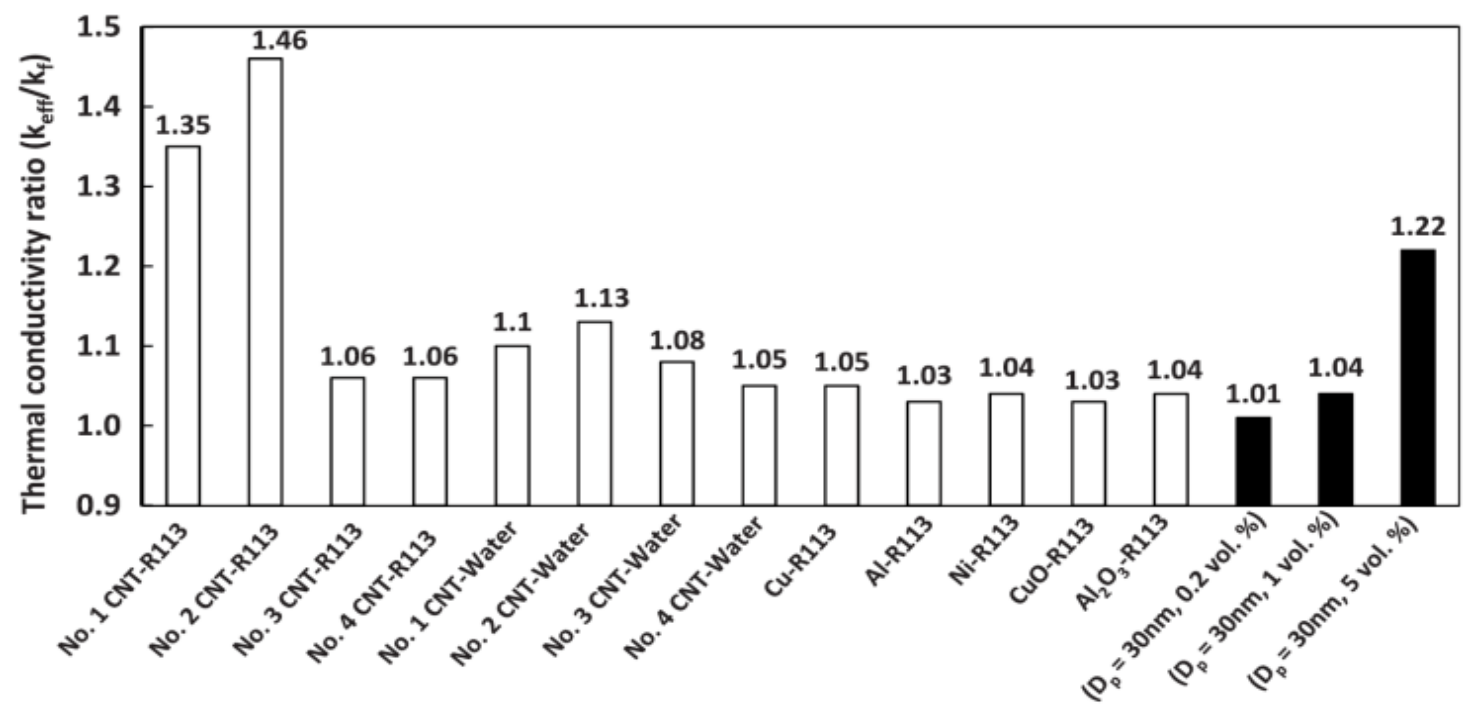

Figure 4. Comparison of $\mathrm{k}_{\mathrm{eff}} / \mathrm{k}_{\mathrm{f}}$ values of nanorefrigerants for different types of nanoparticles, base fluids, and particle concentrations [23].

\subsection{Viscosity}

Viscosity is an important factor to be considered in the case of nanorefrigerants, as a variation in viscosity affects the pressure drop, and consequently, affects the pumping capacity. Mehbubul et al. [26] investigated the variation in viscosity of $\mathrm{TiO}_{2} / \mathrm{R} 123$ nanorefrigerant by varying the temperature from 5 to $20{ }^{\circ} \mathrm{C}$, and volume concentration from 0 to $2 \%$. The authors concluded that viscosity increased with higher volume concentration of nanoparticles, and decreased as temperature was increased. This trend is similar to the one observed in the previously carried out work on the viscosity variation of nanorefrigerants. Figure 5 shows that the viscosity of $\mathrm{TiO}_{2} / \mathrm{R} 123$ increased as the nanoparticle concentration is increased. The authors indicated that the variation in the rate of increase in viscosity, when compared with the results of previous work $[27,28]$, was due to the experimental setup, stability of nanofluids, and agglomeration of nanoparticles. Figure 6 shows the variation in viscosity of a nanorefrigerant with temperature for different concentrations of nanoparticles. It follows the previously indicated trend of decrease in viscosity with increase in temperature. 


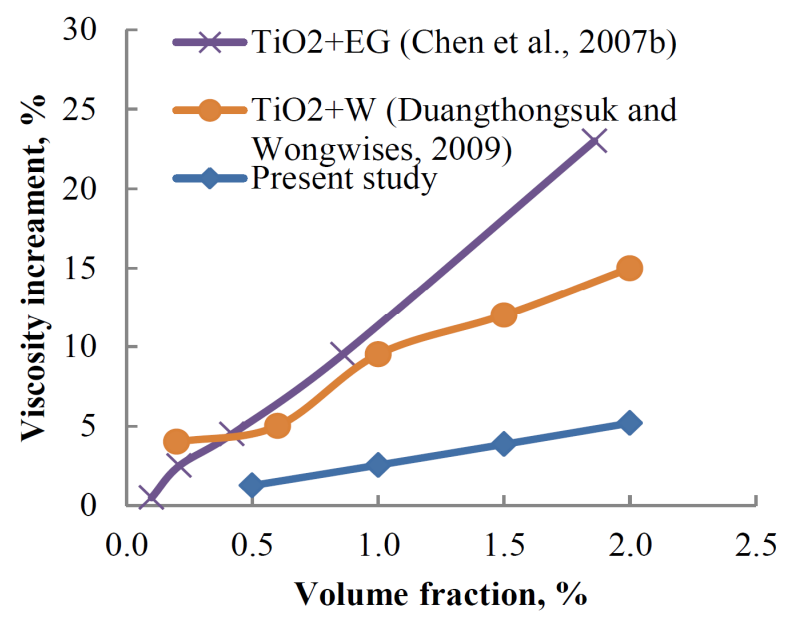

Figure 5. Increase in viscosity with the increase in particle volume fraction (W: Water, EG: Ethylene Glycol) [26].

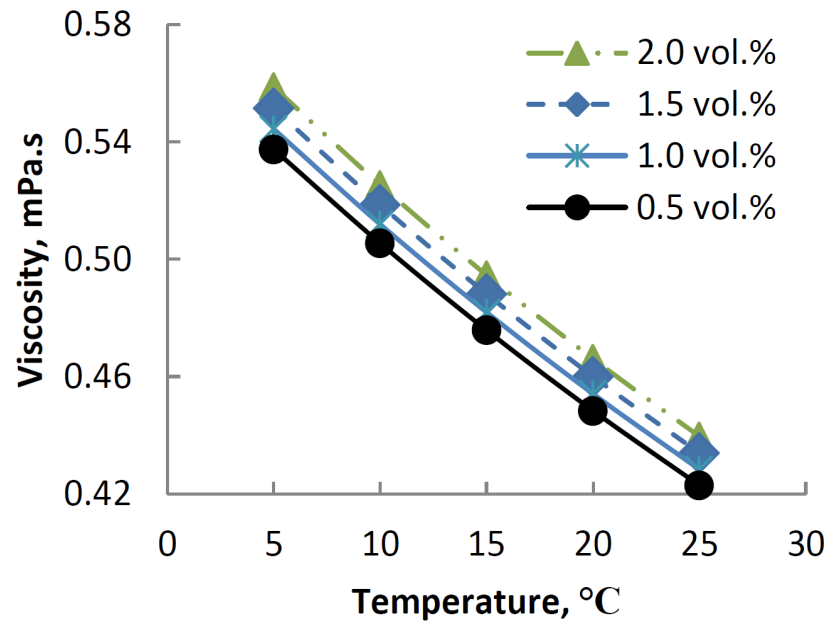

Figure 6. Effect of temperature on viscosity of nanorefrigerants [26].

As mentioned earlier, this is due to intensified Brownian motion at higher temperatures [29,30]. The highest viscosity was observed at $5{ }^{\circ} \mathrm{C}$ and $2 \mathrm{vol} \%$ concentration. In addition, due to the importance of the nanolubricants, which were defined as lubricants with dispersed nanoparticles and the process of design and formulation of lubricants for better performance, it is important to perform investigations related to viscosity and density. Viscosity plays a critical role as far as a compressor is concerned. There are distinct requirements for lubricant viscosity used in compressors. Kedzierski [31] investigated the kinematic viscosity of $\mathrm{Al}_{2} \mathrm{O}_{3}$ / synthetic polyolester which is used as a nanolubricant. The author considered a temperature range of 288 to $318 \mathrm{~K}$ with two different diameters of nanoparticles: 60 and $10 \mathrm{~nm}$, respectively. To maintain proper dispersion of the spherical nanoparticles, surfactants were used. The mass fractions of the nanoparticles and surfactants were used as variable parameters. In addition, the author developed a model to predict the kinematic viscosity, considering the viscosities of the mixture of the nanoparticle, the surfactant, and the base fluid, as a function of temperature, nanoparticle mass fraction, surfactant mass fraction, and nanoparticle diameter. Figures 7 and 8 show the variation in kinematic viscosity with temperature at atmospheric pressure, for nanoparticle diameters of 10 and $60 \mathrm{~nm}$, respectively. A three-dimensional display in Figure 9 indicates that the viscosity decreases with the increase in mass fraction of surfactant in the temperature range of 288 to $300 \mathrm{~K}$, while for the temperature range of 300 to $318 \mathrm{~K}$, the opposite trend was observed. 


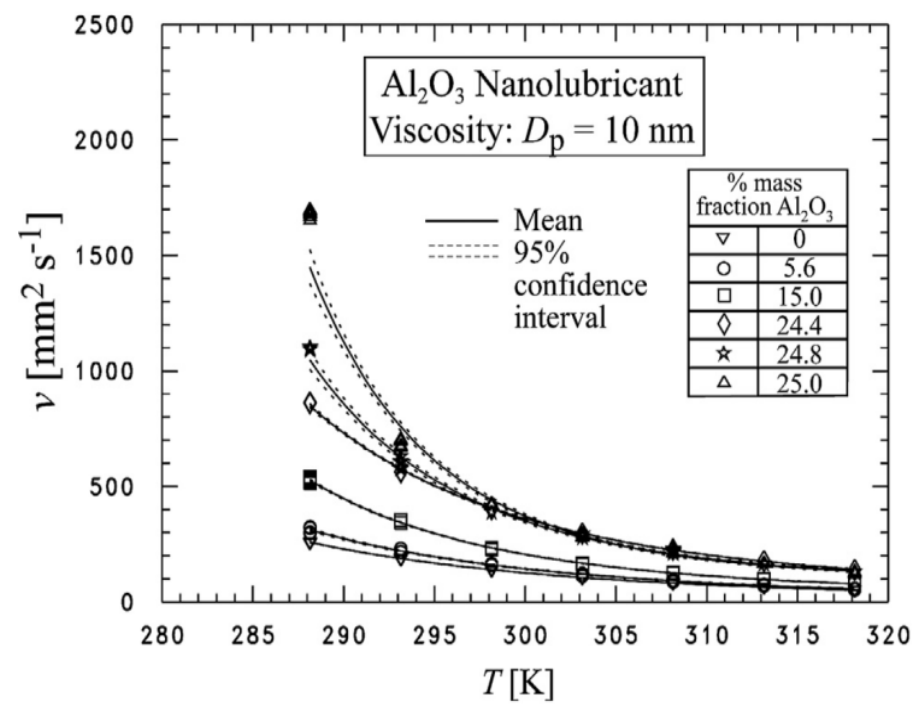

Figure 7. Kinematic viscosity of $\mathrm{Al}_{2} \mathrm{O}_{3}$ nanolubricant with $10 \mathrm{~nm}$ diameter nanoparticles for various mass fractions and temperatures (measured at atmospheric pressure) [31].

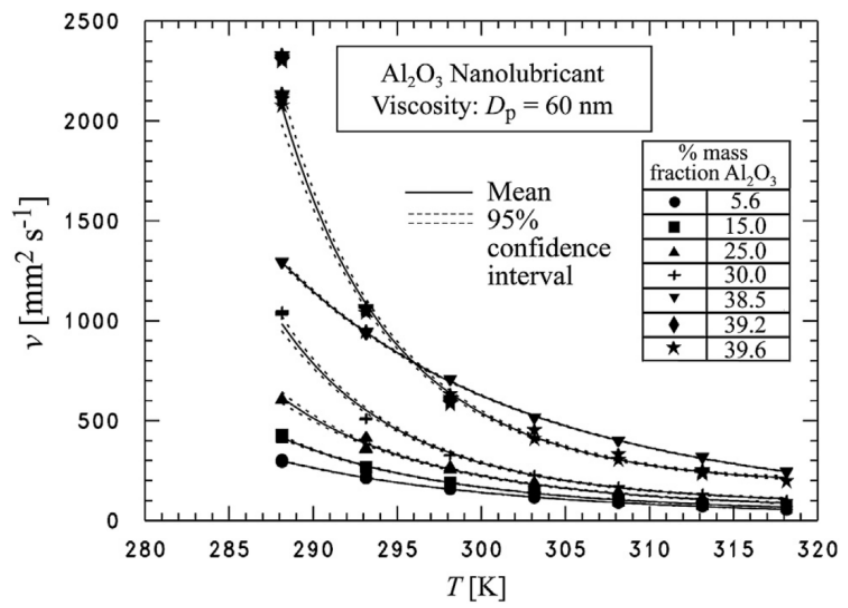

Figure 8. Kinematic viscosity of $\mathrm{Al}_{2} \mathrm{O}_{3}$ nanolubricant with $60 \mathrm{~nm}$ diameter nanoparticles for various mass fractions and temperatures (measured at atmospheric pressure) [31].
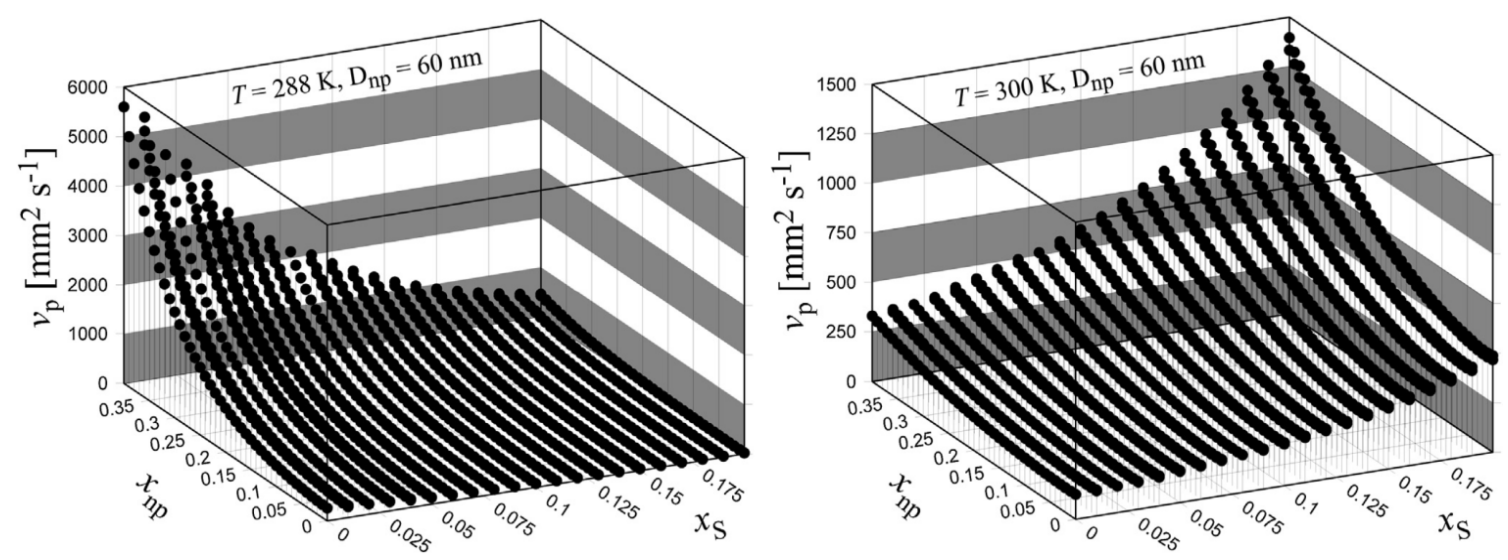

Figure 9. Effect of surfactant mass fraction $\left(\mathrm{X}_{\mathrm{S}}\right)$ and temperature on $\mathrm{Al}_{2} \mathrm{O}_{3}$ nanolubricant $\left(\mathrm{X}_{\mathrm{np}}\right)$ viscosity [31]. 


\subsection{Density}

For proper lubrication performance of a compressor, the viscosity and density of the nanolubricant are important. Kedzierski [32] experimentally studied the variation of viscosity and density of $\mathrm{CuO}$ nanolubricant with different nanoparticle mass fractions $(2.9 \%, 5.6 \%$ and $39.2 \%)$ for a temperature range of 288 to $318 \mathrm{~K}$ with spherical nanoparticles of diameter of $30 \mathrm{~nm}$. Figure 10 shows that the density of the $\mathrm{CuO}$ nanolubricant decreases with temperature at atmospheric pressure. The author also concluded that, density increases with an increase in the $\mathrm{CuO}$ mass fraction.

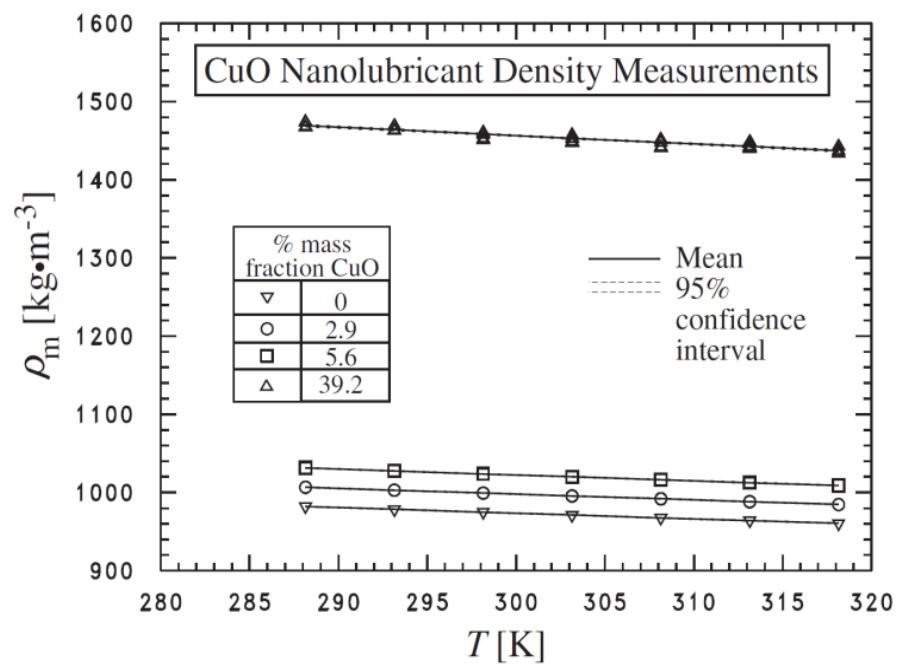

Figure 10. Density of $\mathrm{CuO}$ nanolubricant for various mass fractions (measured at atmospheric pressure) [32].

From the above reviewed articles, it can be seen that the thermal and physical properties largely affect the behavior of nanorefrigerants. Thermal conductivity influences the heat transfer characteristics of nanorefrigerants, whereas viscosity and density influence the pumping capacity. When the nanoparticle concentration is increased, thermal conductivity increases, because the thermal conductivity of the nanoparticles is higher than that of the base fluid. In addition, viscosity and density also increase when the nanoparticle concentration is increased. The various investigations conducted in the last decade on this topic suggest that the investigations are now focusing on other properties also, instead of focusing only on thermal conductivity. In addition, researchers are more interested in determining the optimum values of nanoparticle variables to have an overall optimized result.

\section{Performance Characteristics of Refrigeration Systems}

Nanorefrigerants are considered a promising option to improve the performance of various thermal systems like refrigeration and air conditioning because nanorefrigerants will improve the heat transfer performance of refrigeration systems. Previous research indicates that the use of nanorefrigerants instead of base refrigerants in refrigeration systems can provide several benefits. Higher thermal conductivity and improved heat transfer characteristics can largely alter the overall performance of the system [33]. Nanorefrigerants may or may not affect the solubility of the refrigerant in the lubricant. Bobbo et al. [34] found that there is no significant effect on solubility of R134a when $\mathrm{TiO}_{2}$ and single wall carbon nanohorns (SWCNH) were dispersed. Whereas, contrary to this, Wang et al. [35] suggested that $\mathrm{TiO}_{2}$ nanoparticles show appreciable influence on solubility to make hydro-flurocarbons refrigerants and lubricant more soluble. In addition, nanolubricants can reduce the friction coefficient and wear rate [36]. Most of the refrigeration systems based on vapor compression use lubricating oil for compressors. Refrigeration systems are closed processes, and some lubricating oil flows through all the parts along with refrigerant. Especially, the suspended nanoparticles in base 
refrigerant considerably affect the thermo-physical properties of refrigerants, which subsequently enhances the overall performance of refrigeration systems. The use of nanorefrigerants enhances the solubility of the refrigerant in the lubricant and improves the stability of the lubricant [37]. Bi et al. [38] have concluded that nanolubricants can return more oil to the compressor as compared to systems based on pure refrigerants. Considering the need for energy reduction along with the challenges of global warming and ozone depletion, the use of nanorefrigerants can be a potential game changer. The following section summarizes the performance characteristics of refrigeration systems with nanorefrigerants and nanolubricants.

\subsection{COP (Coefficient of Performance)}

Mehbubul et al. (2015) [39] analyzed the effect of temperature on thermal conductivity, viscosity, density, and specific heat of $\mathrm{Al}_{2} \mathrm{O}_{3} / \mathrm{R} 134 \mathrm{a}$ nanorefrigerant. Additionally, the authors also examined the effects of modified thermo-physical properties on the COP of the nanorefrigerant and compared them with the effects of a base fluid. Figure 11 shows the effect of thermal conductivity on the COP of a system with $\mathrm{Al}_{2} \mathrm{O}_{3} / \mathrm{R} 134 \mathrm{a}$ nanorefrigerant and a system with a base fluid, in the temperature range used for this study. The COP increases with the increase in the temperature. The highest rise of $15 \%$ in the COP was found at higher temperatures because of higher thermal conductivity. For investigating the effect of viscosity on the COP, the authors considered the 134a refrigerant and $\mathrm{Al}_{2} \mathrm{O}_{3} / \mathrm{R} 134 a$ nanorefrigerant with $5 \mathrm{vol} \%$ concentration.

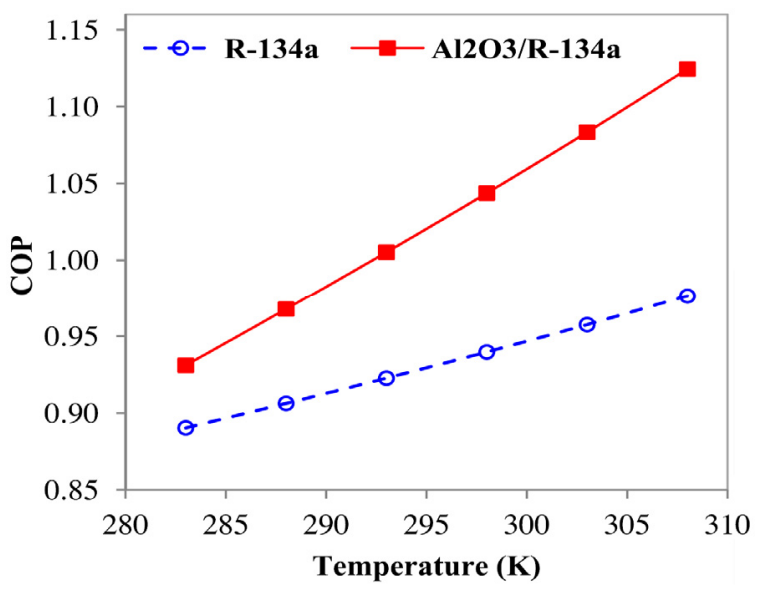

Figure 11. Effect of the thermal conductivity of $\mathrm{Al}_{2} \mathrm{O}_{3} / \mathrm{R}-134$ a nanorefrigerant on COP at different temperatures [39].

Figure 12 demonstrates the effect of viscosity on the COP as the temperature is increased. Although nanorefrigerant has higher viscosity than the base fluid, the nanorefrigerant-based system showed higher COP, as there was no substantial increase in pressure drop. The COP values for both $\mathrm{Al}_{2} \mathrm{O}_{3} / \mathrm{R} 134 \mathrm{a}$ and $\mathrm{R} 134 \mathrm{a}$ refrigerant systems increased with the increase in temperature. Because of higher density, the nanorefrigerant system had 3.2\% higher COP. For centrifugal compressors, pressure rise is related to refrigerant density. A high rise in pressure indirectly reduces the overall pressure drop, and hence improves the performance. Very little study has been done so far on the effect of specific heat on the COP. In their study, the authors present the effect of specific heat on the COP considering different temperatures. The COP was found to be $2.6 \%$ more for a nanorefrigerant as compared to that for a base fluid. Figure 13 shows the effect of the specific heat of $\mathrm{Al}_{2} \mathrm{O}_{3} / \mathrm{R}-134 \mathrm{a}$ nanorefrigerant on the $\mathrm{COP}$ at different temperatures. Xing et al. [40] proposed Fullerene $\mathrm{C}_{60}$ nano-oil as a potential lubricating oil for compressors used in refrigeration systems to improve the performance characteristics of domestic refrigerators. The authors investigated the lubricity and stability of nanoparticle suspension, and found that for a nanoparticles concentration of $1-3 \mathrm{~g} / \mathrm{L}$, the friction coefficient decreased by 
$12.9 \%-19.6 \%$ with respect to that of a pure mineral oil. Figure 14 shows that the compressor work of EMX40CLC and EMU32CLP for the nanoparticle suspension and pure mineral oil were reduced by $4.58 \%$ and $4.52 \%$, respectively, which ultimately increased the COP of EMX40CLC and EMU32CLP by $5.6 \%$ and $5.3 \%$, respectively.

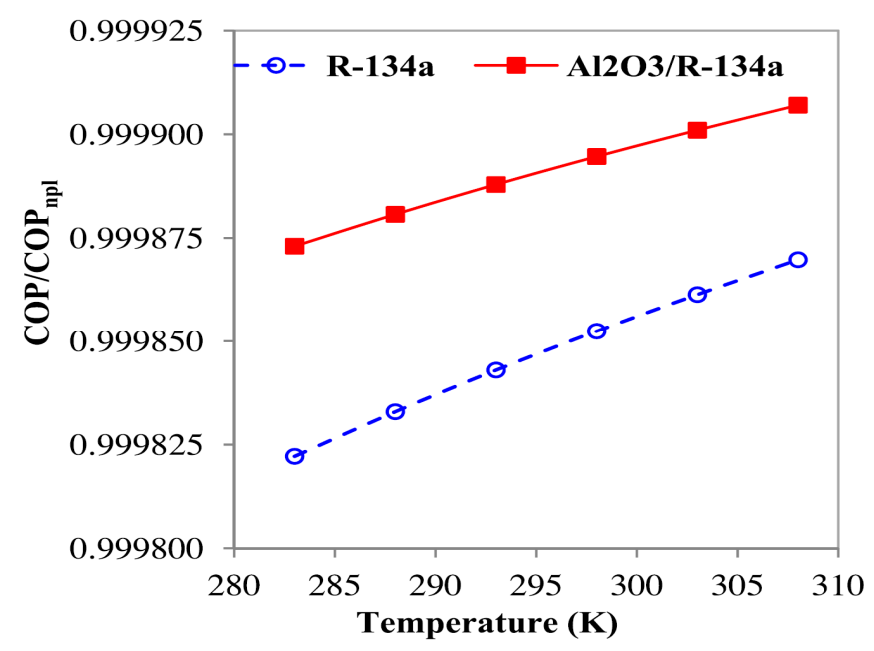

Figure 12. Effect of the viscosity of $\mathrm{Al}_{2} \mathrm{O}_{3} / \mathrm{R}-134$ a nanorefrigerant on $\mathrm{COP}$ at different temperatures (npl: no pressure loss) [39].

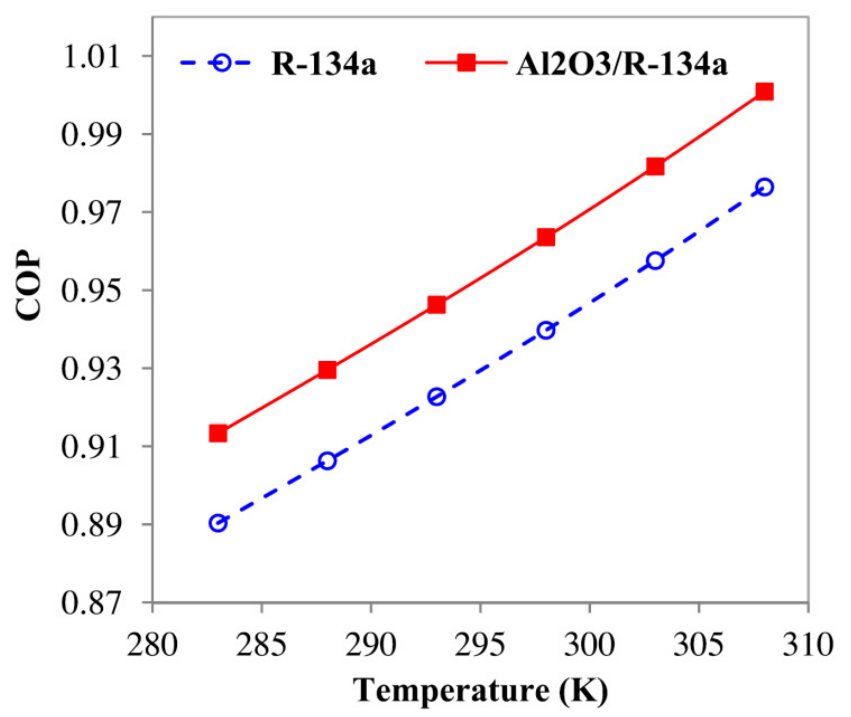

Figure 13. Effect of the specific heat of $\mathrm{Al}_{2} \mathrm{O}_{3} / \mathrm{R}-134 \mathrm{a}$ nanorefrigerant on COP at different temperatures [39].

EMX40CLC and EMU32CLP are hermetic reciprocating compressors with different displacements of 7.24 and $5.96 \mathrm{~cm}^{3}$, respectively. Sabareesh et al. [41] investigated the performance of a vapor compression system with $\mathrm{TiO}_{2}$ nanoparticles in mineral oil, with base refrigerant $\mathrm{R} 12$ as the working fluid. The authors found that the COP of the nanolubricant was higher and observed that there was an optimum value of the volume fraction. The authors observed an increase in the heat transfer rate by $3.6 \%$ and a reduction in compressor work by $11 \%$, which ultimately resulted in a $17 \%$ increase in the COP. They also suggested that $0.01 \%$ is the optimum volume fraction for obtaining the best performance. 


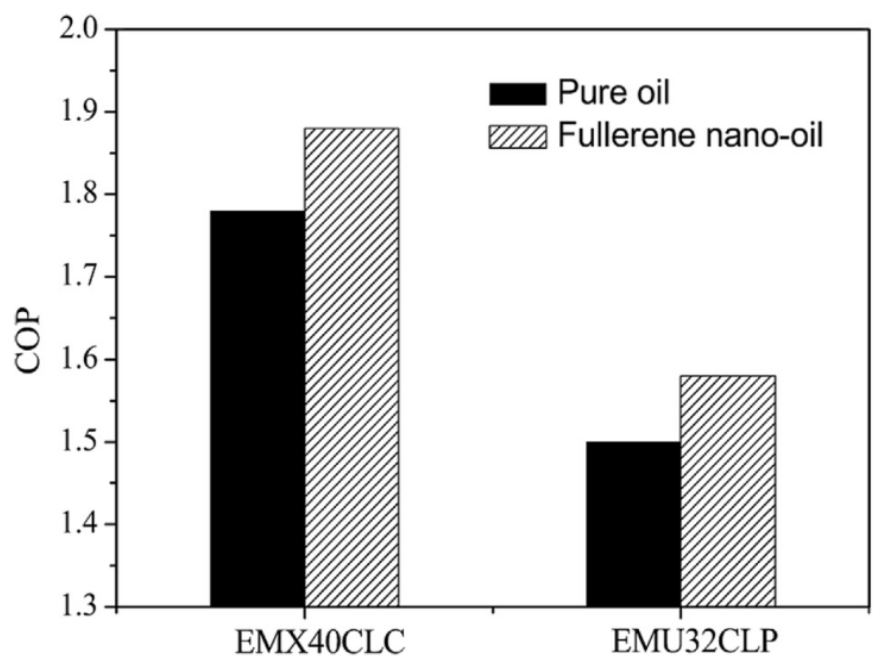

Figure 14. The results of compressor performance testing on COP [40].

\subsection{Energy Consumption}

Bi et al. [42] conducted an energy consumption test and freezing capacity test on a domestic refrigerator in which $\mathrm{TiO}_{2} / \mathrm{R} 600 \mathrm{a}$ nanorefrigerant was used. The authors found that the refrigerator with nanorefrigerant consumed $9.6 \%$ less energy with $0.5 \mathrm{~g} / \mathrm{L} \mathrm{TiO}_{2} / \mathrm{R} 600$ a nanorefrigerant as compared to one with base refrigerant. A nanorefrigerant-based refrigerator showed reduced compressor suction and discharge pressure, and the largest reduction was observed for a concentration of $0.5 \mathrm{~g} / \mathrm{L}$. The authors have claimed that the test was conducted multiple times to ensure repeatability. Figures 15 and 16 show the reduction in suction and discharge pressure of compressor. The results were similar to those obtained in previous work [43]. The authors also showed that the evaporation temperature, fresh food storage compartment temperature, and frozen food storage compartment temperature were also lower, indicating better cooling performance. Table 1 summarizes the system parameter from the energy consumption test and Table 2 shows the energy consumption results. From Table 1, it can be observed that the evaporator temperature is decreasing as the nanoparticle content is increased. From Table 2 , it is observed that $9.6 \%$ energy is saved when nanoparticle concentration is increased from 0 to $0.5 \mathrm{~g} / \mathrm{L}$.

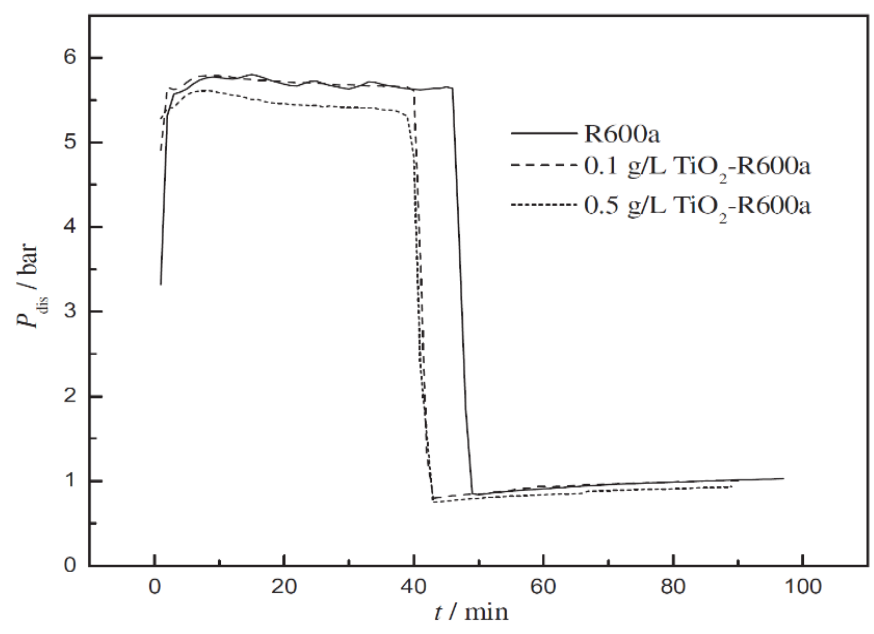

Figure 15. Compressor discharge pressure [42]. 


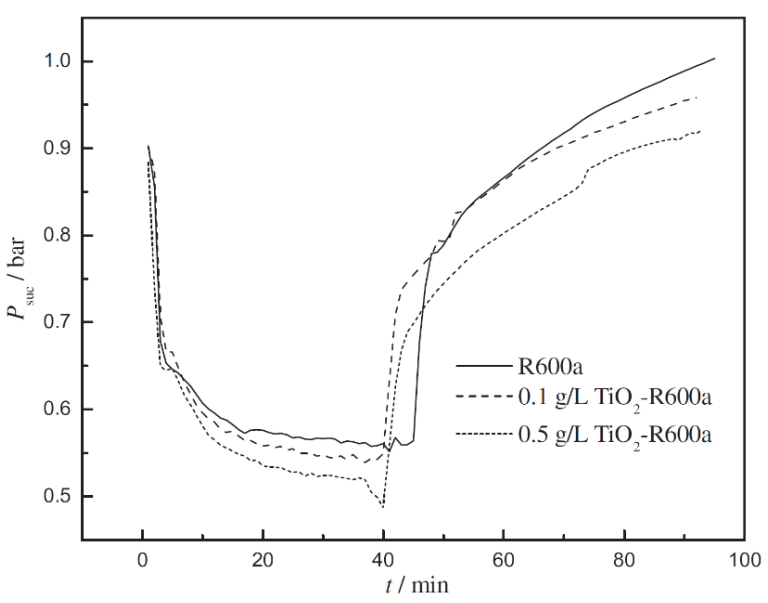

Figure 16. Compressor suction pressure [42].

Table 1. Energy consumption test results [42].

\begin{tabular}{cccccccccc}
\hline $\begin{array}{c}\text { Proportion } \\
(\mathrm{g} / \mathrm{L})\end{array}$ & $\begin{array}{c}\boldsymbol{T}_{\mathrm{fd}} \\
\left({ }^{\circ} \mathbf{C}\right)\end{array}$ & $\begin{array}{c}\boldsymbol{T}_{\mathrm{fz}} \\
\left({ }^{\circ} \mathbf{C}\right)\end{array}$ & $\begin{array}{c}\text { On-Time } \\
\text { Ratio }(\%)\end{array}$ & $\begin{array}{c}\boldsymbol{P}_{\text {suc }} \\
(\mathbf{b a r})\end{array}$ & $\begin{array}{c}\boldsymbol{P}_{\text {dis }} \\
(\mathbf{b a r})\end{array}$ & $\begin{array}{c}\boldsymbol{T}_{\text {dom }} \\
\left({ }^{\circ} \mathbf{C}\right)\end{array}$ & $\begin{array}{c}\boldsymbol{T}_{\text {Evp }} \\
\left({ }^{\circ} \mathbf{C}\right)\end{array}$ & $\begin{array}{c}\boldsymbol{T}_{\text {Cond }} \\
\left({ }^{\circ} \mathbf{C}\right)\end{array}$ & $\begin{array}{c}\boldsymbol{T}_{\text {Room }} \\
\left({ }^{\circ} \mathbf{C}\right)\end{array}$ \\
\hline 0 & 5.33 & -18.13 & 46.67 & 0.595 & 5.611 & 42.14 & -24.30 & 33.87 & 25.91 \\
0.1 & 5.40 & -18.80 & 44.12 & 0.583 & 5.700 & 45.09 & -24.96 & 34.91 & 24.99 \\
0.5 & 5.36 & -19.06 & 43.39 & 0.574 & 5.463 & 47.18 & -25.14 & 34.18 & 25.27 \\
\hline
\end{tabular}

Table 2. Energy consumption results [42].

\begin{tabular}{cccc}
\hline Concentration $(\mathrm{g} / \mathrm{L})$ & 0 & 0.1 & 0.5 \\
Energy consumption $(\mathrm{kW} \cdot \mathrm{h})$ & 0.9567 & 0.8999 & 0.8649 \\
Energy saving $(\%)$ & $/$ & 5.94 & 9.6 \\
\hline
\end{tabular}

Subramani et al. [44] conducted experimental studies on an R134a refrigeration system by introducing a mixture of mineral oil and alumina nanoparticles instead of POE (polyolester) oil. The authors found that the freezing capacity was higher, and power consumption reduced by $25 \%$. In addition, the enhancement factor for the evaporator was 1.53, and the COP was $33 \%$ higher for the nanorefrigerant as compared to the base refrigerant. Jwo et al. [12] conducted an experiment by replacing R143a with a hydrocarbon refrigerant, and polyester lubricant with a mixture of mineral oil and $\mathrm{Al}_{2} \mathrm{O}_{3}$ nanoparticles. The authors found that with $60 \% \mathrm{R} 134 \mathrm{a}$ and $0.1 \mathrm{wt} \% \mathrm{Al}_{2} \mathrm{O}_{3}$ nanoparticles, the power consumption reduced by $2.4 \%$ and the COP increased by $4.4 \%$. Table 3 shows the results of the experiments done with the freezer for a continuous load of $10 \mathrm{~W}$.

\subsection{Nanolubricants}

Bi et al. [38] performed an experiment on a domestic refrigerator by replacing polyolester oil with a mixture of mineral oil and $\mathrm{TiO}_{2}$ nanoparticles. The authors conducted an energy consumption test and freezer capacity test. Table 3 shows the energy consumption test results, which indicates a reduction of $26.1 \%$ in energy consumption for $0.1 \%$ mass fraction of $\mathrm{TiO}_{2}$ as compared to the POE oil system.

Table 3. Energy consumption of HFC134a/POE oil and HFC134a/mineral oil/ $\mathrm{TiO}_{2}$ nanoparticle systems [38].

\begin{tabular}{ccccc}
\hline Mass Fraction \% & POE & $\mathbf{0 . 0 6} \mathbf{T i O}_{\mathbf{2}}$ & $\mathbf{0 . 1} \mathbf{T i O}_{\mathbf{2}}$ & $\mathbf{0 . 1} \mathbf{T i O}_{\mathbf{2}} \mathbf{~ ( 5 0 ~ D a y s ~ L a t e r ) ~}^{\text {(5) }}$ \\
\hline Energy consumption $(\mathrm{kW}$ h/day) & 1.077 & 0.849 & 0.796 & 0.8 \\
Energy saving \% & - & 21.2 & 26.1 & 25.7 \\
\hline
\end{tabular}


Figure 17 shows that the freezing rate is slightly higher with the system with nanoparticles as compared to the POE oil system. The authors concluded that along with performance, the solubility between refrigerant and lubricant was also improved. Kedzierski [45] investigated the boiling performance of $\mathrm{R} 134 \mathrm{a}$ / polyolester mixture using different $\mathrm{CuO}$ nanoparticle concentrations. The author found $140 \%$ higher boiling heat flux in case of $4 \% \mathrm{CuO}$ volume fraction as compared to $2 \% \mathrm{CuO}$ Volume fraction and attributed this result to the threshold $\mathrm{CuO}$ volume fraction. In addition, the author discussed the heat transfer mechanisms involved in the boiling performance. For boiling performance enhancement or degradation, the author speculated three mechanisms such as nanoparticle-bubble interaction, thermal conductivity enhancement due to accumulation of highly conductive nanoparticles, and degradation of boiling performance due to blocking of the nucleation sites by the nanoparticles.

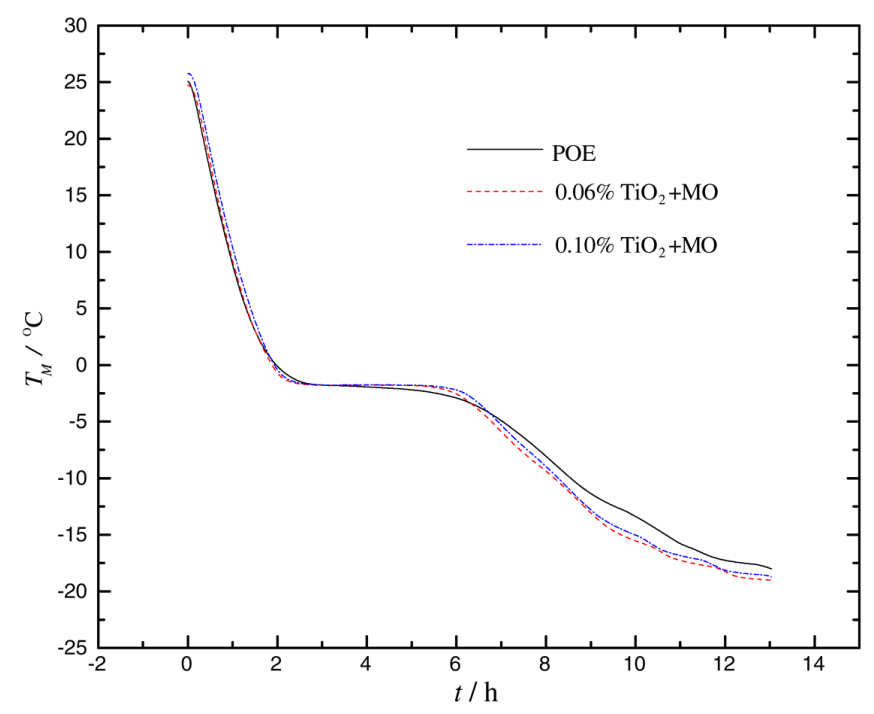

Figure 17. Freezing capacities of HFC134a/POE oil and $\mathrm{HFC134a/mineral} \mathrm{oil/} \mathrm{TiO}_{2}$ nanoparticle systems [38].

Based on the articles reviewed, it can be inferred that the use of nanorefrigerants in refrigeration systems can improve the performance of the systems. Nanoparticles can be used as nanorefrigerants in the base refrigerant or as nanolubricants in the lubricating oil. The results from the investigations indicate an improvement in the COP of the refrigeration system. However, very little attention has been given to the issues related to the nanolubricant usage in the refrigeration system. The issues related to long-term stability should also be addressed before the nanorefrigerants are commercialized.

\section{Conclusions}

Based on extensive research on the thermal physical properties and performance characteristics of refrigerant-based nanofluids, this review covers judiciously selected articles published in the open literature from 2005 to 2015 . This survey is divided into two parts. The first part reviewed the articles on the thermal and physical properties of nanorefrigerants for various refrigeration systems. The second part dealt with the performance characteristics of the refrigeration systems based on nanorefrigerants and nanolubricants. Extensive studies have been performed experimentally, theoretically, and numerically on the thermal and physical properties and the performance of refrigerant-based nanofluids. Particularly in the last decade, various investigations have been performed and reported on nanorefrigerants because of their superior properties and applicability to refrigeration systems. Because of the enhanced properties and better performance, nanorefrigerants and nanolubricants have proven to be a promising option for efficient refrigeration systems. The following part concludes a few important findings from the reviewed articles. 
- Based on the literature review done on nanorefrigerants, it is observed that the thermal conductivity of a nanorefrigerant is higher than that of the base fluid. It is confirmed that the thermal conductivity increases with the volume concentration/mass fraction of nanoparticles in the working fluid.

- As CNT (carbon nano tube) has exceptionally high thermal conductivity, the thermal conductivity of CNT-based nanorefrigerants was found to be higher as compared to other nanorefrigerants.

- When the nanoparticle size is increased, the thermal conductivity is found to decrease, although the surface area increased on account of the larger size of the nanoparticles.

- When compared with different types of nanoparticles, CNT-based nanorefrigerants showed the maximum increase in thermal conductivity.

- The viscosity of nanorefrigerants was found to increase with the increase in particle volume fraction and decrease with the increase in temperature.

- When the mass fraction of the surfactant was increased, viscosity was found to be increased for a synthetic polyolester based aluminium oxide nanoparticles and polymeric surfactant for temperature range of 300 to $318 \mathrm{~K}$.

- The density of $\mathrm{CuO}$ nanolubricant decreased with increase in temperature.

- The highest rise in the COP of $15 \%$ in an $\mathrm{Al}_{2} \mathrm{O}_{3} / \mathrm{R} 34$ a system was found at higher temperatures because of enhanced thermal conductivity.

- A reduction of $11 \%$ in compressor work was observed when the $\mathrm{TiO}_{2}$ nanoparticles were suspended in mineral oil and used with a base refrigerant.

- Nanorefrigerant-based systems consumed $9.6 \%$ less energy with $0.5 \mathrm{~g} / \mathrm{L} \mathrm{TiO}-\mathrm{R} 600 \mathrm{a}$ nanorefrigerant as compared to a system with a base refrigerant.

Acknowledgments: This work was supported by the Dong-A University research fund.

Author Contributions: Mahesh Suresh Patil (F.A) and Moo-Yeon Lee (C.A) organized and wrote the paper. Jae-Hyeong Seo and Sung Chul Kim are the co-authors and commented on the review and summary of the published articles in the main parts in the paper.

Conflicts of Interest: The authors declare no conflict of interest.

\section{Nomenclature}

MWCNT Multiwall carbon nanotube

CNT Carbon nanotube

EG Ethylene glycol

$\mathrm{X}_{\mathrm{np}} \quad$ Mass fraction of nanoparticles

$\mathrm{X}_{\mathrm{S}} \quad$ Mass fraction of surfactant

$\mathrm{T}_{\text {suc }} \quad$ Compressor suction temperature

$\mathrm{T}_{\text {cond }} \quad$ Condenser temperature

$\mathrm{T}_{\text {dis }} \quad$ Compressor discharge temperature

$\mathrm{T}_{\text {dom }} \quad$ Compressor dome temperature

$\mathrm{T}_{\mathrm{fz}} \quad$ Frozen food storage compartment evaporator temperature

$\mathrm{T}_{\mathrm{fd}} \quad$ Fresh food storage compartment evaporator inlet temperature

$\mathrm{T}_{\text {evp }} \quad$ Evaporator temperature

$\mathrm{P}_{\mathrm{suc}} \quad$ Compressor suction pressure

$\mathrm{P}_{\text {dis }} \quad$ Compressor discharge pressure 


\section{References}

1. Wen, D.; Lin, G.; Vafaei, S.; Zhang, K. Review of nanofluids for heat transfer applications. Particuology 2007, 7, 141-150. [CrossRef]

2. Liu, Z.; Xiong, J.; Bao, R. Boiling heat transfer characteristics of nanofluids in a flat heat pipe evaporator with micro-grooved heating surface. Int. J. Multiph. Flow 2007, 33, 1284-1295. [CrossRef]

3. Wen, D.; Ding, Y. Experimental investigation into the pool boiling heat transfer of aqueous based- $\mathrm{Al}_{2} \mathrm{O}_{3}$ nanofluids. J. Nanopart. Res. 2005, 7, 265-274. [CrossRef]

4. Bang, I.; Chang, S. Boiling heat transfer performance and phenomena of $\mathrm{Al}_{2} \mathrm{O}_{3}$-water nano-fluids from a plain surface in a pool. Int. J. Heat Mass Transf. 2005, 48, 2407-2419. [CrossRef]

5. You, S.; Kim, J.; Kim, K. Effect of nanoparticles on critical heat flux of water in pool boiling heat transfer. Appl. Phys. Lett. 2003, 83, 3374-3376. [CrossRef]

6. Torii, S. Experimental study on thermal transport phenomenon of nanofluids as working fluid in heat exchanger. Int. J. Air-Cond. Refrig. 2014, 22, 1450005:1-1450005:6. [CrossRef]

7. Sözen, A.; Özbaş, E.; Menlik, T.; Çakır, M.T.; Gürü, M.; Boran, K. Improving the thermal performance of diffusion absorption refrigeration system with alumina nanofluids: An experimental study. Int. J. Refrig. 2014, 44, 73-80. [CrossRef]

8. Saidur, R.; Leong, K.Y.; Mohammad, H.A. A review on applications and challenges of nanofluids. Renew. Sust. Energ. Rev. 2011, 15, 1646-1668. [CrossRef]

9. Yang, D.; Sun, B.; Li, H.W.; Fan, X.C. Experimental study on the heat transfer and flow characteristics of nanorefrigerants inside a corrugated tube. Int. J. Refrig. 2015, 56, 213-223. [CrossRef]

10. Smalley, R.E. Future global energy prosperity: The terawatt challenge. In Material Matters; MRS Bulletin: Warrendale, PA, USA, 2005; pp. 412-417.

11. Alawi, O.A.; Sidik, N.A.C.; Beriache, M. Applications of nanorefrigerant and nanolubricants in refrigeration, air-conditioning and heat pump systems: A review. Int. Commun. Heat Mass Transf. 2015, 68, 91-97. [CrossRef]

12. Jwo, C.S.; Jeng, L.Y.; Teng, T.P.; Chang, H. Effects of nanolubricant on performance of hydrocarbon refrigerant system. J. Vac. Sci. Technol. B 2009, 27, 1473-1477. [CrossRef]

13. Alawi, O.A.; Sidik, N.A.C.; Mohammed, H.A. A comprehensive review of fundamentals, preparation and applications of nanorefrigerants. Int. Commun. Heat Mass Transf. 2014, 54, 81-95. [CrossRef]

14. Celen, A.; Çebi, A.; Aktas, M.; Mahian, O.; Dalkilic, A.S.; Wongwises, S. A review of nanorefrigerants: Flow characteristics and applications. Int. J. Refrig. 2014, 44, 125-140. [CrossRef]

15. Saidur, R.; Kazi, S.N.; Hossain, M.S.; Rahman, M.M.; Mohammed, H.A. A review on the performance of nanoparticles suspended with refrigerants and lubricating oils in refrigeration systems. Renew. Sust. Energ. Rev. 2011, 15, 310-323. [CrossRef]

16. Philip, J.; Shima, P.D. Thermal properties of nanofluids. Adv. Colloid Interface Sci. 2012, 183-184, 30-45. [CrossRef] [PubMed]

17. Buongiorno, J.; Venerus, D.C.; Prabhat, N.; McKrell, T.; Townsend, J.; Christianson, R.; Tolmachev, Y.V.; Keblinski, P.; Hu, L.-W.; Alvarado, J.L.; et al. A benchmark study on the thermal conductivity of nanofluids. J. Appl. Phys. 2009, 106. [CrossRef]

18. Alawi, O.A.; Sidik, N.A.C. Mathematical correlations on factors affecting the thermal conductivity and dynamic viscosity of nanorefrigerants. Int. Commun. Heat Mass Transf. 2014, 58, 125-131. [CrossRef]

19. Jiang, W.; Ding, G.; Peng, H.; Gao, Y.; Wang, K. Experimental and model research on nanorefrigerant thermal Conductivity. HVACER Res. 2009, 15, 651-669.

20. Alawi, O.A.; Sidik, N.A.C. Influence of particle concentration and temperature on the thermophysical properties of $\mathrm{CuO} / \mathrm{R} 134 a$ nanorefrigerant. Int. Commun. Heat Mass Transf. 2014, 58, 79-84. [CrossRef]

21. Koo, J.; Kleinstreuer, C. A new thermal conductivity model for nanofluids. J. Nanopart. Res. 2004, 6, 577-588. [CrossRef]

22. Mahbubul, I.M.; Saidur, R.; Amalina, M.A. Influence of particle concentration and temperature on thermal conductivity and viscosity of $\mathrm{Al}_{2} \mathrm{O}_{3} / \mathrm{R} 141 \mathrm{~b}$ nanorefrigerant. Int. Commun. Heat Mass Transf. 2013, 43, 100-104. [CrossRef] 
23. Mahbubul, I.M.; Fadhilah, S.A.; Saidur, R.; Leon, K.Y.; Amalina, M.A. Thermophysical properties and heat transfer performance of $\mathrm{Al}_{2} \mathrm{O}_{3} / \mathrm{R}-134$ a nanorefrigerants. Int. J. Heat Mass Transf. 2013, 57, 100-108. [CrossRef]

24. Sitprasert, C.; Dechaumphai, P.; Juntasaro, V. A thermal conductivity model for nanofluids including effect of the temperature-dependent interfacial layer. J. Nanopart. Res. 2009, 11, 1465-1476. [CrossRef]

25. Leong, K.C.; Yang, C.; Murshed, S.M.S. A model for the thermal conductivity of nanofluids-The effect of interfacial layer. J. Nanopart. Res. 2006, 8, 245-254. [CrossRef]

26. Mahbubul, I.M.; Saidur, R.; Amalina, M.A. Investigation of viscosity of $\mathrm{R} 123-\mathrm{TiO}_{2}$ nanorefrigerant. Int. J. Mech. Mat. Eng. 2012, 7, 146-151.

27. Duangthongsuk, W.; Wongwises, S. Measurement of temperature-dependent thermal conductivity and viscosity of $\mathrm{TiO}_{2}$-water nanofluids. Exp. Therm. Fluid Sci. 2009, 33, 706-714. [CrossRef]

28. Chen, H.; Ding, Y.; Tan, C. Rheological behaviour of nanofluids. New J. Phys. 2007, 9. [CrossRef]

29. Kulkarni, D.P.; Das, D.K.; Chukwu, G.A. Temperature Dependent Rheological Property of Copper Oxide Nanoparticles Suspension (Nanofluid). J. Nanosci. Nanotechnol. 2006, 6, 1150-1154. [CrossRef] [PubMed]

30. Namburu, P.K.; Kulkarni, D.P.; Misra, D.; Das, D.K. Viscosity of copper oxide nanoparticles dispersed in ethylene glycol and water mixture. Exp. Therm. Fluid Sci. 2007, 32, 397-402. [CrossRef]

31. Kedzierski, M.A. Viscosity and density of aluminum oxide nanolubricant. Int. J. Refrig. 2013, 36, 1333-1340. [CrossRef]

32. Kedzierski, M.A. Viscosity and density of CuO nanolubricant. Int. J. Refrig. 2012, 35, 1997-2002. [CrossRef]

33. Jiang, W.; Ding, G.; Peng, H. Measurement and model on thermal conductivities of carbon nanotube nanorefrigerants. Int. J. Therm. Sci. 2009, 48, 1108-1115. [CrossRef]

34. Bobbo, S.; Fedele, L.; Fabrizio, M.; Barison, S.; Battiston, S.; Pagura, C. Influence of nanoparticles dispersion in POE oils on lubricity and R134a solubility. Int. J. Refrig. 2010, 33, 1180-1186. [CrossRef]

35. Wang, R.; Wu, Y.; Xie, G. Use of nano-particles $\left(N-\mathrm{TiO}_{2}(R)\right)$ to make hydro-fluorocarbons refrigerants more compatible with oil lubricants. In Proceedings of the IIR-IRHACE International Conference on Innovative Equipment and Systems for Comfort and Food Preservation, Auckland, New Zealand; 2006; pp. 205-212.

36. Lee, K.; Hwang, Y.; Cheong, S.; Kwon, L.; Kim, S.; Lee, J. Performance evaluation of nano-lubricants of fullerene nanoparticles in refrigeration mineral oil. Curr. Appl. Phys. 2009, 9, e128-e131. [CrossRef]

37. Lin, L.; Peng, H.; Ding, G. Dispersion stability of multi-walled carbon nanotubes in refrigerant with addition of surfactant. Appl. Therm. Eng. 2015, 91, 163-171. [CrossRef]

38. Bi, S.; Shi, L.; Zhang, L. Application of nanoparticles in domestic refrigerators. Appl. Therm. Eng. 2008, 28, 1834-1843. [CrossRef]

39. Mahbubul, I.M.; Saadah, A.; Saidur, R.; Khairul, M.A.; Kamyar, A. Thermal performance analysis of $\mathrm{Al}_{2} \mathrm{O}_{3} / \mathrm{R}-134 a$ nanorefrigerant. Int. J. Heat Mass Transf. 2015, 85, 1034-1040. [CrossRef]

40. Xing, M.; Wang, R.; Yu, J. Application of fullerene $\mathrm{C}_{60}$ nano-oil for performance enhancement of domestic refrigerator compressors. Int. J. Refrig. 2014, 40, 398-403. [CrossRef]

41. Sabareesh, R.K.; Gobinath, N.; Sajith, V.; Das, S.; Sobhan, C.B. Application of $\mathrm{TiO}_{2}$ nanoparticles as a lubricant-additive for vapor compression refrigeration systems-An experimental investigation. Int. J. Refrig. 2012, 35, 1989-1996. [CrossRef]

42. Bi, S.; Guo, K.; Liu, Z.; Wu, J. Performance of a domestic refrigerator using $\mathrm{TiO}_{2}-\mathrm{R} 600 \mathrm{a}$ nano-refrigerant as working fluid. Energy Conv. Manag. 2011, 52, 733-737. [CrossRef]

43. Bi, S.; Shi, L. Experimental investigation of a refrigerator with a nanorefrigerant. J. Tsinghua Univ. 2007, 47, 1999-2002.

44. Subramani, N.; Prakash, M.J. Experimental studies on a vapour compression system using nanorefrigerants. Int. J. Eng. Sci. Technol. 2011, 3, 95-102. [CrossRef]

45. Kedzierski, M.A. Effect of CuO nanoparticle concentration on R134a/lubricant pool boiling heat transfer. In Proceedings of the MNHT2008 Micro/Nanoscale Heat Transfer International Conference, Tainan, Taiwan, 6-9 January 2008.

(C) 2015 by the authors; licensee MDPI, Basel, Switzerland. This article is an open access article distributed under the terms and conditions of the Creative Commons by Attribution (CC-BY) license (http://creativecommons.org/licenses/by/4.0/). 